\title{
Injury Pattern Among Non-fatal Road Traffic Crash Victims
}

\author{
K. Gichuhi, MBBS, MMed (Surg.), Ortho Glasgow, Consultant Orthopaedic Surgeon, Kenyatta National Hospital, \\ Honorary Lecturer, Department of Orthopaedic Surgery, College of Health Sciences, University of Nairobi, \\ P.O. Box 19983-00202, Nairobi, Kenya, Email: kgichuhidr@yahoo.com
}

\begin{abstract}
Objective: To study and analyse the pattern of injuries among non-fatal road traffic crash victims.

Design: Retrospective analytical study.

Setting: Kenyatta National Hospital, Nairobi over a six-month period from February to July 2004.

Subjects: Road traffic crashes victims treated at Kenyatta National Hospital, Nairobi during the period under study.

Results: One thousand four hundred and twenty four victims of road traffic crashes were treated over a sixmonth period. The male: female ratio was $3: 1$ and the pedestrians were the majority (69.7\%). The commonest injuries were fractures (69.0\%) and the tibia/fibula being the most fractured bones (30.3\%). Age group 15-44 years was the most affected $(81.9 \%)$. There was one incidence of a ruptured eye in a passenger.
\end{abstract}

Conclusion: Road traffic injuries are a major cause of death and disability globally with disproportionate number occurring in the developing countries. The most affected age group 15-44 years lead to double tragedy to these countries with loss of productive man-hours and expenditure incurred to treat them.

\section{INTRODUCTION}

Road traffic injuries are currently ranked ninth globally among the leading causes of disability adjusted to life years lost, and the ranking projected to rise to third by year 2020 (1). These injuries are a major cause of death and disability globally with disproportionate number occurring in the developing countries.

In developing countries road traffic injuries particularly affect the economically active cohort with peak age 15-44 years. This is a double tragedy to these countries, mainly because of the productive man-hours lost and expenditure incurred to treat them.

Though this is a pilot study it is hoped that it will stimulate further expansive studies. Availability of empirical data in our setting would not only reveal the magnitude of the problem but would also help in identifying the target groups so that a scientific approach to prevention can be planned. The data would also assist in identifying the areas to be strengthened in post injury management of the victims.

\section{MATERIALS AND METHODS}

The study was carried out at Kenyatta National Hospital, Nairobi. All the non-fatal victims of road traffic crashes reporting to Kenyatta National Hospital, Casualty Department between February and July 2004 were included in this study. Using the victims' records, the demographic and injury characteristics were recorded on a predesigned proforma. The collected data was analysed using SPSS ${ }^{\oplus} 11.5$ version.

\section{RESULTS}

A total of 1424 victims of road traffic crashes were treated at Kenyatta National Hospital, Casualty Department during the period between $1^{\text {st }}$ February 2004 and $31^{\text {st }}$ July 2004.

The males were 1063 (74.6\%) and 361 (25.4\%) females making male female ratio 3:1.

These were divided into six categories of pedestrians, passengers, drivers, cyclists, motorcyclists and mkokoteni (a large non-motorised cart used to ferry goods) pushers. The distribution of the different categories is as shown in Table 1 and the pedestrians comprised the highest percentage (69.7\%). The pedestrians were injured while crossing the road $(62.5 \%)$ and the rest (32.5\%) while walking along the road.

The gender distribution in the different categories is as shown in Table 2. 
Table 1

Category distribution of victims

\begin{tabular}{lcc}
\hline Category & Frequency & $(\%)$ \\
\hline Pedestrian & 993 & 69.7 \\
Passenger & 292 & 20.5 \\
Cyclist & 72 & 5.1 \\
Driver & 51 & 3.6 \\
Mkokoteni ${ }^{*}$ pusher & 8 & 0.6 \\
Motorcyclist & 8 & 0.6 \\
\hline Total & 1424 & 100 \\
\hline
\end{tabular}

* A large non-motorised cart used to ferry goods

Table 2

Gender and category distribution

\begin{tabular}{lccc}
\hline Category & Male & Female & Total \\
\hline Pedestrian & 756 & 238 & 994 \\
Passenger & 170 & 122 & 292 \\
Driver & 50 & 1 & 51 \\
Cyclist & 71 & 0 & 71 \\
Mkokoteni ${ }^{*}$ pusher & 8 & 0 & 8 \\
Motorcyclist & 8 & 0 & 8 \\
\hline
\end{tabular}

* A large non-motorised cart used to ferry goods

The ages of the victims ranged from 1 year to 75 years and the ages were divided into groups of five years starting from 0-4 years up to $70+$ age groups. The age groups 15-19 years up to $40-44$ years were the most affected (Table 3 ) and comprising $81.9 \%$ of the total victims.

Table 3

Age groups distribution

\begin{tabular}{lcc}
\hline Age group (years) & Freguency & $(\%)$ \\
\hline $0-4$ & 23 & 1.6 \\
$5-9$ & 63 & 4.4 \\
$10-14$ & 40 & 2.8 \\
$15-19$ & 92 & 6.5 \\
$20-24$ & 264 & 18.5 \\
$25-29$ & 280 & 19.7 \\
$30-34$ & 267 & 18.8 \\
$35-39$ & 143 & 10.0 \\
$40-44$ & 119 & 8.4 \\
$45-49$ & 51 & 3.6 \\
$50-54$ & 42 & 2.9 \\
$55-59$ & 18 & 1.3 \\
$60-64$ & 9 & 0.6 \\
$65-69$ & 7 & 0.5 \\
$70+$ & 6 & 0.4 \\
\hline Total & 1424 & 100 \\
\hline
\end{tabular}

The areas injured were recorded as head, face, neck, thorax, abdomen, thoracic spine, lumbar spine, upper extremity lower extremity and pelvis. There were 590 (41.4\%) victims injured in two areas and 107 (7.5\%) injured in more than two areas. The most frequent type of injury was fractures (69.0\%) followed by head injury (25.6\%) (Table 4). The most common fractures seen were tibia fibula (30.3\%) followed by femoral (12.4\%). For the 119 victims who had head injury, 25 of them had fracture skull seen on skull radiographs whereas the rest was clinical diagnosis. 
Table 4

Injury type distribution

\begin{tabular}{lcc}
\hline Injury type & Frequency & $(\%)$ \\
\hline Fracture & 322 & 69.0 \\
Head injury & 119 & 25.6 \\
Dislocation & 12 & 2.6 \\
Blunt abdominal injury & 6 & 1.3 \\
Cervical spine injury & 4 & 0.9 \\
Lumbar spinal injury & 1 & 0.2 \\
Ruptured eye & 1 & 0.2 \\
Haemopneumothorax & 1 & 0.2 \\
\hline Total & 467 & 100 \\
\hline
\end{tabular}

A total of 362 (25.4\%) victims had sustained injuries, which required inpatient management. There were 221 (61.4\%) victims admitted in the Orthopaedic wards and 125 (34.5\%) in General Surgical wards (Table 5).

Table 5

\begin{tabular}{lcc}
\multicolumn{3}{c}{ Admission distribution } \\
\hline & Frequency & $(\%)$ \\
\hline Orthopaedic & 221 & 61.0 \\
General Surgical & 125 & 34.5 \\
Paediatric Surgical & 13 & 3.6 \\
ICU & 2 & 0.6 \\
Ophthalmology & 1 & 0.3 \\
\hline Total & 362 & 100
\end{tabular}

\section{DISCUSSION}

The present study carried at Kenyatta National Hospital, Nairobi revealed that most of the road crash victims are in age group 15-44 years. Earlier studies have also reported high incidence of road traffic injuries in similar age groups (2-6). The male: female ratio was 3:1.

The pedestrians formed the majority of victims $(69.7 \%)$ as compared to the passengers $(20.5 \%)$ in this study. This could be attributed to the fact that in year 2004 there was an introduction and enforcement of legislation that all passenger vehicles install speed 'governors' limiting the speed to $80 \mathrm{~km} / \mathrm{hr}$ and roadworthy inspection of the vehicles before being allowed on the road. This measures reduced the number of passengers injured in buses and minibuses (7).

The pedestrians were injured while crossing roads (62.5\%) or walking along the road (32.5\%). In Nairobi there are few pedestrian friendly walkways and the Nairobi City Council is blocking the few available in order to discourage hawkers who tend to display their merchandise in any open space including walkways and pavements. Construction of bumps and rumble strips have been shown to be effective in taming the vehicle speeds especially in areas with high density of pedestrians crossing the road (8).

The most common injuries were fractures (69.0\%) with fractures tibia/fibula being the most recorded (30.3\%). Other studies have reported similar observations (6).

\section{REFERENCES}

I. Murray C. and Lopez A. The global burden of disease. vol.1 Cambridge M.A. Harvard University Press. 1996.

2. Sathiyasekwan B.W.C. Study of the injured and the pattern in road traffic accidents. Indian J. Forensic. Sci. 1991; 5: 63-68.

3. Gosh P.K. Epidemiology of the victims of vehicular accidents in Delphi. J. Indian Med. Assoc. 1992; 90: 309312.

4. Balogun J.A. and Abereoje O.K. Pattern of road traffic accidents cases in a Nigerian University Teaching Hospital between 1987 and 1990. J. Trop. Med. Hyg. 1992; 95: 23-29.

5. Nantulya V.M. and Reich M.R.The neglected epidemic: Road traffic injuries in developing countries. Brit. Med. J. 2002; 324: 1139-1141.

6. Ganveer G.B. and Tiwari R.R. Injury pattern among nonfatal road traffic cases: A cross-sectional study in Central India. Indian J. Med. Sci. 2005; 59: 9-12.

7. Museru L.M,. Mcharo C.N. and Leshabari M.T. Road traffic accidents in Tanzania: A ten-year epidemiological appraisal. East \& Central Afr. J. Surg. 2002; 7: 23-26.

8. Nantulya V.M. and Muli-Musiime F. Kenya. Uncovering the social determinants of the road traffic accidents. In: Evans T., Whitehead M., Diderichsen F., Bhuiya A.,Wirth M., eds. Challenging inequities from ethics to action. Oxford: Oxford University Press. 2001. 